\title{
Attitude Components Affecting Functional Dairy Foods Acceptance Among Iranian Urban Consumers
}

Mohammad Kavoosi-Kalashami ( $\sim$ mkavoosi@guilan.ac.ir)

University of Guilan https://orcid.org/0000-0003-1789-4496

AmirAli Faridi

University of Guilan

Hamid El Bilali

Istituto Agronomico Mediterraneo di Bari

\section{Research}

Keywords: Functional dairy foods, Healthy lifestyle, General components of purchasing, Structural equation, Iran.

Posted Date: August 24th, 2020

DOl: https://doi.org/10.21203/rs.3.rs-61780/v1

License: (c) (i) This work is licensed under a Creative Commons Attribution 4.0 International License. Read Full License 


\section{Abstract}

Background: Due to the effects that chemical and inorganic foods have on the human body system and cause a variety of diseases, including cancer, the use of functional foods is highly recommended for people. In this study, the attitudinal factors affecting the acceptance of functional dairy foods by urban consumers in Rasht, located in Guilan province, have been investigated.

Methods: Data were obtained from 223 households in Rasht City, Northern Iran. Structural Equation Modeling (SEM) was used to investigate the effects of the general components of purchasing, the benefits of functional dairy food, the need of functional dairy foods, confidence in functional dairy foods, safety of functional dairy foods, health consciousness and healthy lifestyle, components on the willingness to buy of functional dairy foods.

Results: The components of attitude towards healthy lifestyle and the general components of purchasing were the most effective factors in determining the acceptance of functional dairy foods by the households of Rasht City.

Conclusions: Lifestyle changes and promotion of healthy lifestyle among urban consumers will increase the acceptance of functional dairy foods in Iran.

\section{Background}

Health is one of the frequently mentioned motivations when consumers make their food choices [37, 53]. The term was first coined in Japan in 1994 and functional foods were considered as "food products fortified with special constituents that possess advantageous physiological effects" [35]. According to The International Life Sciences Institute [3], functional foods are those that include a variety of relevant components to improve health status or reduce the risk (non-prevention) of the disease. When fortified with special constituents, some of the functional foods can not only enhance physiological functions but also reduce disease risks, resulting in improved physical and mental well-being of men and women [36, $52,39,45]$. Functional foods thus represent an important growth category for the commercial sector in many countries around the world [50]. Diplock et al. [17] gave a widely adopted working definition, which describes a functional food as a food that "affect[s] beneficially one or more target functions of the body, beyond adequate nutritional effects, in a way that is relevant to either an improved state of health and wellbeing and/or reduction of risk of disease."

The steady increase in life expectancy, the desire of older people for improved quality of their later lives, and the increasing cost of healthcare are the main reasons that explain why there is an increasing demand for functional foods designed to confer health benefits [45-46]. Bimbo et al. [9] estimate the market value for food with health claims at $\$ 168$ billion in 2013, with an annual average growth rate of $8.5 \%$, and it is forecasted to exceed $\$ 300$ billion by 2020 . Nearly $90 \%$ of American adults acknowledge the benefits of functional food. Food companies attracted by this potential have been investing in the development of new nutritionally modified and functional products [32]. In Iran, the demand of functional 
dairy foods and the opportunities of development on the market seem to be quite favorable and the awareness of the consumers is relatively high.

In addition to the commercial sector, the academic and governmental sectors have also focused on functional food development over the past decade. Numerous studies indicate that consumers are increasingly reflective in matters of health and willingness to adopt health-oriented changes in their eating habits $[41,44,48]$. There are more and more consumers believing that foods contribute directly to their health $[40,62]$. However, the absence of a universally accepted definition is one of the major difficulties encountered in assessing the potential health benefits from such foods [10, 38, 27, 47]. Human food choice is a function of a multitude of influences. Such a complex food choice process influences food production systems and consumers' nutrient intake as it determines what foods consumers buy and eat [19].

Several factors influence the choice of specific types of goods by consumers. Knowing more about these factors and their impact on purchasing choices will help policymakers move towards maximizing consumer satisfaction and boosting the market. The mechanisms of functional food choice are similar to the choice of the so-called conventional food products, but there might be differences in the perceptions of the benefits of using functional foods [56-57]. With recent advancements in modern food science and technology, the food industry can now provide increasingly sophisticated methods for controlling and altering the physical structure and the chemical composition of a food product.

Functional foods promise improved health, better well-being, or enhanced functioning of physiological processes. The importance placed on one's health is correlated with the intention to purchase functional foods [55]. Consumers' beliefs in the health benefits of functional foods constitute an important factor affecting acceptance of these products [58]. Therefore, people concerned about their health should be more interested in functional foods [23].

Increasingly affluent and ageing populations have become more concerned with protecting their health through diet. Consumers' acceptance of the concept of functional foods and a better understanding of its determinants are widely recognized as key success factors in successfully negotiating market opportunities and consumer-led market orientation $[2,21,24,58,59,61]$. As a consequence, there is a growing number of studies addressing cognitive, motivational, and attitudinal determinants of consumers' acceptance of functional foods and/or their willingness to use them in different countries [7$8,16,22,30,31,34-43,56-57-58]$.

However, none of these studies examined all the attitude components simultaneously. Moreover, there is a research gap regarding the context of Iran as all these studies were carried out in other countries (e.g. Hungary, Italy, Germany). This research analyses the impact of different attitude components on the consumption and acceptance of functional dairy foods in Iran, taking into account all the known components in previous studies and using the structural equation approach. 
Despite much research into functional foods, not all people in a community are prepared to accept these foods. It is important to investigate whether or not local consumers with varying levels of health consciousness and contradictory healthy lifestyles will have diverse attitudes toward functional foods and will differ in their willingness to use for functional dairy products. The findings are hoped to provide some recommendations to the marketing agents in the functional dairy foods industry to develop marketing strategies and facilitate these products consumption in the society.

Therefore, this study investigated the prominent attitude components affecting the consumption of functional dairy foods among urban Iranian consumers. The functional dairy foods used in this study were as follows:

(1) Milk enriched with vitamin D. Vitamin D is a fat-soluble bioactive vitamin, which is sensitive to light, heat and oxygen [6].

(2) Probiotic yogurt. Probiotic yogurt is among the most popular probiotic products [33, 54]. Nowadays, probiotics are included in many products in order to promote the growth of probiotics consumption. Therefore, incorporation of probiotics into fermented milks such as yogurt, especially those containing probiotic bacteria, would potentially lead to a healthier product. It is argued that prebiotics may aid survival of probiotics in fermented milks during processing and storage [11].

(3) Probiotic cheese (Cheddar cheese). Cheddar cheese may offer certain advantages over yogurt-type products in terms of delivery of viable probiotics, such as the reduced acidity of the cheese compared to yogurt environments and the high fat content and texture of Cheddar cheese may offer protection to the microorganisms during passage through the gastrointestinal tract (GIT) [51].

\section{Theoretical Framework}

The conceptual framework of this study is shown in Fig. 1. The attitudinal components used in this study are: general purchasing component, benefits of functional dairy foods, need of functional dairy foods, confidence in functional dairy foods, safety of functional dairy foods, health consciousness and healthy life style.

The hypotheses considered in the study are as follows:

H1. The general purchasing component has a positive and significant effect on the acceptance of functional dairy foods.

H2. The benefits of functional dairy foods component have a positive and significant effect on the acceptance of functional dairy foods.

H3. The necessity of the functional dairy foods component has a positive and significant effect on the acceptance of functional dairy foods. 
H4. The confidence in functional dairy foods component has a positive and significant effect on the acceptance of functional dairy foods.

H5. The Safety of functional dairy foods component has a positive and significant effect on the acceptance of functional dairy foods.

H6. The health consciousness component has a positive and significant effect on the acceptance of functional dairy foods.

H7. The healthy lifestyle component has a positive and significant effect on the acceptance of functional dairy foods.

\section{Methods}

In order to achieve the study goals, a questionnaire was used as the research tool. Face-to-face interview with 223 local residents in Rasht City during July 2016 used for data collection.

In the first part of the questionnaire, individual characteristics such as gender, education, occupation, number of family members, income, and age were included. In the second part, the items of different attitude components (i.e. general purchasing component, benefits of functional dairy foods, necessity of functional dairy foods, confidence in functional dairy foods, safety of functional dairy foods, health consciousness and healthy lifestyle) were addressed.

To assess the reliability of the questionnaire, 30 pretest questionnaires were completed. Moreover, 10 experts were consulted and their views were applied in the questionnaire. The duration of the interviews was 15-30 minutes, and questions were provided in Persian language. Before interviewing respondents, the purpose of the research was explained to them and their agreement was received.

Using Structural Equation Model (SEM) technique provides more advantage for parameter estimation and model testing than first generation techniques such as factor analysis, principal component analysis and regression analysis as it has a "holistic fashion" [30,25]. In this study Smart-PLS was used as software. Since the research is an early stage assessment of functional dairy foods acceptance and all items in the data are not normally distributed ( $p<0.01$ based on Kolmogorov-Smirnov's test), the partial least squares (PLS) is the most appropriate method for this study [25-26]. It is also suggested to use PLS-SEM when predicting key target constructs, or identifying key driver constructs [25].

SEM is mostly considered as synonymous with covariance-based SEM, which is well known and commonly preferred. But it falls short for small data sets, which cannot satisfy its assumptions. PLSSEM does not have strict assumptions such as distribution, sample size and measurement scale. So, it enables research with small data sets $[49,60]$.

Especially for the indicators which are formative in nature, CB-SEM appears to be more problematic than PLS-SEM [15]. The PLS-SEM modeling algorithm presents the outer and inner estimation stages. Thus, 
PLS-SEM analysis is completed in two consecutive steps. In the first step, the assessment of measurement model is performed. A number of non-parametric assessment criteria such as construct reliability $(>0.6)$, outer loadings $(>0.7)$, indicator reliability $(0.5)$, and average variance extracted $(0.5)$ must be satisfied to prove that the measurement model can be used in the structural model [5]. In the second step, results of the structural model are evaluated. With this purpose, bootstrapping and blindfolding procedures are advised. These procedures provide R2 measures, and the level and the significance of path coefficients $[13,25]$.

\section{Results And Discussion}

Table 1 shows the descriptive statistics of individuals' demographics.

Table 1

Socio-demographics of the respondents $(n=223)$

\begin{tabular}{|c|c|c|c|c|}
\hline Variable & Definition & Frequency (\%) & Mean & Std. Dev. \\
\hline \multirow[t]{2}{*}{ Gender } & Male & 71.4 & - & - \\
\hline & Female & 28.6 & - & - \\
\hline \multirow[t]{7}{*}{ Education } & Illiterate & 0.89 & - & - \\
\hline & Lower than diploma & 13 & - & - \\
\hline & Diploma & 39.4 & - & - \\
\hline & Associate degree & 12.1 & - & - \\
\hline & Bachelor & 26.4 & - & - \\
\hline & MA & 7.17 & - & - \\
\hline & $\mathrm{PhD}$ & 0.89 & - & - \\
\hline \multirow[t]{7}{*}{ Occupation } & Expert & 12.1 & - & - \\
\hline & Self-employed & 42.15 & - & - \\
\hline & Employee & 15.6 & - & - \\
\hline & Housewife & 9.8 & - & - \\
\hline & Manual worker & 6.72 & - & - \\
\hline & Unemployed & 13.4 & - & - \\
\hline & & & - & - \\
\hline Family size & Number of family members & - & 3.65 & 1.078 \\
\hline Age & In years & - & 36.39 & 33.904 \\
\hline
\end{tabular}


Various factors affect the willingness of urban consumers to buy functional dairy foods. Several components were used in the questionnaire. Descriptive statistics of components used in estimating the PLS model were shown in Table 2.

Table 2

Descriptive statistics of attitude components.

\begin{tabular}{|lllll|}
\hline Component & Average & S.D. & Max. & Min. \\
\hline General purchasing component (GPC) & 13.71 & 0.23 & 17 & 1 \\
\hline Benefits of functional dairy foods (BF) & 13.03 & 0.20 & 16 & 0 \\
\hline Necessity of functional dairy foods (NF) & 6.07 & 0.12 & 8 & 1 \\
\hline Confidence in functional dairy foods (CF) & 8.82 & 0.19 & 12 & 0 \\
\hline Safety of functional dairy foods (SF) & 8.38 & 0.19 & 12 & 0 \\
\hline Health consciousness (HC) & 9.89 & 0.16 & 12 & 2 \\
\hline Healthy lifestyle (HL) & 6.32 & 012 & 8 & 0 \\
\hline Willingness to use functional dairy foods (WF) & 0.56 & 0.03 & 1 & 0 \\
\hline
\end{tabular}

Outer loadings, composite reliability (CR), average variance extracted (AVE), and discriminant validity were assessed with the aim of measurement model assessment. In Table 3, results of CR, AVE and discriminant validity assessment criteria for each construct are shown. Composite reliability (CR) is above 0.7 (minimum CR is 0.717) indicating that the scales have internal consistency. Average variance extracted (AVE) was used to test convergent validity. AVE should be higher than 0.50 so that the latent variables explain more than half of the variance of its indicators [18, 26, 28-29]. As seen in Table 3, all constructs meet these criteria. The AVE, CR, and Alpha values are higher than the recommended thresholds of $0.5,0.7$, and 0.7 respectively $[4,20,42]$. This demonstrates convergent validity and validity indicating that the constructs can be used to test the conceptual model. The result of the estimation of path coefficients in the structural model and the outer weights in the measurement model performed by the SmartPLS software are shown in Fig. 2.

The path significance levels were estimated using a bootstrap with 500 resamples. The R2 criteria was used to assess the predictive capacity of the structural model (Chin, 1998). General purchasing component $\left(\beta^{\wedge}=0.253, p<0.01\right)$, the benefits of functional dairy foods $\left(\beta^{\wedge}=0.137, p<0.01\right)$, necessity of functional dairy foods $\left(\beta^{\wedge}=0.125, p<0.01\right)$, confidence in functional dairy foods $\left(\beta^{\wedge}=0.221, p<0.01\right)$, safety of functional dairy foods $\left(\beta^{\wedge}=0.198, p<0.01\right)$, health consciousness $\left(\beta^{\wedge}=0.132, p<0.01\right)$ and healthy lifestyle $\left(\beta^{\wedge}=0.227, p<0.01\right)$ had positive and significant effect on dependent variable. Thus, all study hypotheses were confirmed. The results indicated that healthy lifestyle was the most important component in explaining the willingness to use of functional dairy foods $(Y)$ given that when this 
component increases one standardized unit, $\mathrm{Y}$ increases 0.227 standardized units, ceteris paribus. As R2 showed, the model explains $79.5 \%$ of the variation in willingness to use functional dairy foods.

Table 3

PLS model characteristics.

\begin{tabular}{|lllll|}
\hline Variable & CR & AVE & VIF & P-Value \\
\hline GPC & 0.871 & 0.628 & 1.445 & 0.000 \\
\hline BF & 0.867 & 0.621 & 1.605 & 0.001 \\
\hline NF & 0.797 & 0.663 & 1.265 & 0.002 \\
\hline CF & 0.850 & 0.654 & 1.607 & 0.000 \\
\hline SF & 0.841 & 0.638 & 1.506 & 0.000 \\
\hline HC & 0.843 & 0.729 & 1.306 & 0.000 \\
\hline HL & 0.816 & 0.596 & 1.410 & 0.000 \\
\hline WF & 1.000 & 1.000 & - & - \\
\hline
\end{tabular}

Abbreviations: GPC General purchase component, $B F$ Benefits of functional dairy foods, NF Necessity of the functional dairy foods, CF Confidence in functional dairy foods, SF Safety of functional dairy foods, $H C$ Health consciousness, $H L$ Healthy lifestyle, WF Willingness to use functional dairy foods.

Using the 'bootstrapping method', significance of outer weights for germinal reagents was investigated. These weights were shown in Fig. 2 and their significance (t-stat) is shown in Fig. 3.

The results of the study showed that healthy lifestyle had the highest impact on the acceptance of functional dairy foods in Iran. This finding is in line with the results of Chen [12] and can be important for producers and marketers involved in the production and marketing of functional dairy foods.

The next important factor in acceptance of functional dairy foods is the general purchase component. The results suggest that the price of functional dairy foods was very important for consumers. Proper packaging is also important for consumers. This finding is in line with Zhu et al. [63].

\section{Conclusions}

In this study, seven attitudinal factors affecting the acceptance of functional dairy foods were studied and their importance was prioritized. The most effective component in the acceptance of functional dairy foods was the component of healthy lifestyle that had the highest effect. The general purchasing component, confidence in functional dairy foods, safety of functional dairy foods, the benefits of functional dairy foods, health consciousness, and the necessity for functional dairy foods were the next important components, respectively. 
Healthy lifestyle was identified as the most important factor affecting the intake of functional foods. This means that people who have higher life expectancy and care for a healthy lifestyle are consumers of functional dairy foods. In other words, producers in this area can try to better understand the lifestyle of consumers, thus planning and investing with higher returns.

Given the benefits of consuming these products in preventing diseases and reducing health costs at the society level, it is suggested that government subsidies be put on the agenda to reduce the prices of these products and increase their consumption.

The next effective components in consumption was confidence in functional dairy foods. This means that consumers' confidence should increase toward these foods. Raising public awareness toward the benefits of using these products and widespread advertisements in this area can increase public confidence in functional foods.

The safety of functional dairy foods was another component influencing the acceptance of such foods. Experts should also clarify the safety of these products to prevent rumors about these products. Providing documentaries from the place of production and displaying their production process can help the consumers to admit and verify the safety of these products.

Most people do not have enough information about the many benefits of functional dairy foods. Therefore, actions should be taken to better inform consumers about the benefits of these products. Organizing conferences to explain the benefits of functional foods and their impact on the health of the community can be very helpful. It is also important to organize temporary exhibitions for manufacturers of these products, where people can directly view, test, and ultimately purchase them. Providing brochures containing information on the benefits of functional dairy foods, producers, and broadcasting them in public places will be very useful.

Another factor affecting the use of functional dairy foods is health consciousness. So it can be concluded that the greater a person's concern for their health, the more likely they are to buy functional dairy foods. In this context, it is essential to raise public awareness of the importance of their health and to maintain their health by eating healthy foods.

Moreover, it is vital to strengthen research in Iran on functional foods in general and functional dairy foods in particular. Future studies should consider the attitudes of consumers and their willingness to use a variety of functional dairy foods that maintain their health and prevent various diseases. In the present study, the main focus was only on the attitudes affecting the acceptance of functional dairy foods.

\section{Declarations}

\section{Acknowledgments}

Not applicable. 


\section{Authors' contributions}

Data curation, Formal analysis, Visualization, Writing - original draft, A.A.F; Investigation, Methodology, Project administration, Resources, Software, Supervision, Validation, Writing - original draft, M.K.K; Conceptualization, Writing - original draft, Writing - review \& editing, H.E.B.

\section{Funding}

Not applicable.

\section{Consent for publication}

Not applicable.

\section{Competing interests}

All authors declare no potential conflict of interest.

\section{Author details}

$1^{*}$ Ph.D., Assistant Professor, Department of Agricultural Economics, University of Guilan, Iran, Phone: +989113317045, email: mkavoosi@guilan.ac.ir, ORCID ID: 0000-0002-0363-7176

${ }^{2}$ MSc Student of Rural Development, Department of Agricultural Economics, University of Guilan, Iran, Phone: +989129388157, email: amirali.faridi@yahoo.com

${ }^{3}$ Ph.D., Researcher, International Centre for Advanced Mediterranean Agronomic Studies of Bari (CIHEAMBari), Valenzano (Bari), Italy, e-mail: elbilali@iamb.it

\section{References}

1. Apostolidis C, McLeay F. Should we stop meeting like this? Reducing meat consumption through substitution. Food Policy. 2016; 65, 74-89.

2. Ares G, Gámbaro A. Influence of gender, age and motives underlying food choice on perceived healthiness and willingness to try functional foods. Appetite. 2007; 49(1): 148-158.

3. Ashwell M. Concepts of functional food. Nutr. Food Sci. 2004; 34(1): 47.

4. Bagozzi R. P, Yi Y. On the evaluation of structural equation models. J Acad Mark Sci.1988; 16(1): 7494.

5. Bagozzi R. P, Yi, Y, Phillips L. W. Assessing construct validity in organizational research. Adm Sci Q.1991; 421-458.

6. Ballard J. M, Zhu L, Nelson E. D, Seburg R. A. Degradation of vitamin D3 in a stressed formulation: The identification of esters of vitamin D3 formed by a transesterification with triglycerides. J Pharm Biomed Anal.2007; 43(1): 142-150. 
7. Bech-Larsen T, Grunert K. G. The perceived healthiness of functional foods: A conjoint study of Danish, Finnish and American consumers' perception of functional foods. Appetite. 2003; 40(1): 914.

8. Bhaskaran S, Hardley F. Buyer beliefs, attitudes and behavior: Foods with therapeutic claims. J Consum Mark. 2002; 19: 591-606.

9. Bimbo F, Bonanno A, Nocella G, Viscecchia R, Nardone G, De Devitiis B, Carlucci D. Consumers' acceptance and preferences for nutrition-modified and functional dairy products: A systematic review. Appetite. 2017; 113: 141-154.

10. Blades M. Functional foods or nutraceuticals. Nutr Food Sci. 2000; 30: 73-75.

11. Capela P, Hay T, Shah N. Effect of cry protectants, prebiotics and microencapsulation on survival of probiotic organisms in yoghurt and freeze-dried yoghurt. Food Res Int. 2006; 39(2): 203-211.

12. Chen M.F. The joint moderating effect of health consciousness and healthy lifestyle on consumers' willingness to use functional foods in Taiwan. Appetite. 2011; 57(1): 253-262.

13. Chin W. Partial least squares for IS researchers: An overview and presentation of recent advances using the PLS approach. ICIS. 2000; 741-742.

14. Chin W. W. Issues and opinion on structural equation modeling. MIS quarterly. 1998; 22: vii-xvi.

15. Chin W. W. How to write up and report PLS analyses Handbook of partial least squares Springer. 2010; 655-690

16. Cox D. N, Koster A, Russell C. G. Predicting intentions to consume functional foods and 55-6 supplements to offset memory loss using an adaptation of protection motivation theory. Appetite. 2004; 33: 55-64.

17. Diplock A, Aggett $P$, Ashwell M, Bornet F, Fern E, Robertfroid M. Scientific concepts of functional foods in Europe: consensus document. Spec Publ Soc Chem. 2000; 248: 8-60.

18. Fornell C, Larcker D. F. Evaluating structural equation models with unobservable variables and measurement error. J Mark Res. 1981;18(1): 39-50.

19. Furst T, Connors M, Bisogni C. A, Sobal J, Falk L.W. Food choice. A conceptual model of the process. Appetite. 1996; 26: 247-265.

20. Gefen D, Straub D. W, Boudreau M. C. Structural equation modelling and regression: Guidelines for research practice. Commun Assoc Inf Syst. 2000; 4: 1-70.

21. Gilbert L. The consumer market for functional foods. J Nutraceuticals Funct Med Foods. 1997; 1: 521.

22. Gilbert L. The functional food trend. What's next and what Americans think about eggs. J Am Coll Nutr. 2000; 19: 507S-512S.

23. Goetzke B, Nitzko S, Spiller A. Consumption of organic and functional food. A matter of well-being and health? Appetite. 2014; 77: 94-103.

24. Grunert K. G, Bech-Larsen T, Bredahl L. Three issues in consumer quality perception and acceptance of dairy products. Int. Dairy Journal. 2000; 10: 575- 584. 
25. Hair J. F, Ringle C. M, Sarstedt M. PLS-SEM: Indeed, a silver bullet. J Mark Theory Pract. 2011; 19(2): 139-152.

26. Hair J, Sarstedt M, Ringle C, Mena J. An assessment of the use of partial least squares structural equation modeling in marketing research. J Acad Mark Sci. 2012; 40: 414-433.

27. Heasman M, Mellentin J. The functional foods revolution: Healthy people, healthy profits? Routledge. London: Earthscan Publications. 2001.

28. Henseler J, Ringl, C. M, Sinkovics R. R. The use of partial least squares path modeling in international marketing. Adv. Int. Mark. 2009; 20: 277-320.

29. Henseler J, Ringle C. M, Sinkovics R. R. The use of partial least squares path modeling in international marketing. In P. N. Ghauri, \& R. R. Sinkovics (Eds.), New challenges to international marketing (Advances in international marketing) Emerald Group Publishing Limited. 2009; 20: 277319

30. Huotilainen A, Seppala T, Pirttila-Backman A.-M, Tuorila H. Derived attributes as mediators between categorization and acceptance of a new functional drink. Food Qual Prefer. 2006;17: 328-336.

31. Jonas M, Beckmann S.C. Functional foods. Consumer perception in Denmark and England. (No. Working paper no. 55). Aarhus: MAPP-Centre for Marketing Surveillance Research and Strategy for the Food Sector, The Aarhus School of Business. 1998.

32. Khan R. S, Grigor J. V, Win A. G, Boland M. Differentiating aspects of product innovation processes in the food industry: An exploratory study on New Zealand. Br Food Journal. 2014; 116(8): 1346-1368.

33. Korbekandi H, Mortazavian A, Iravani S. Technology and stability of probiotic in fermented milks. Probiotic and prebiotic foods: Technology, stability and benefits to the human health. 2011; 131-169. https://doi.org/10.1007/s13197-014-1516-2.

34. Korzen-Bohr S, O'Doherty J. K. Heart disease among post-menopausal women. Acceptability of functional foods as a preventive measure. Appetite. 2006; 46: 152-163.

35. Kubomura K. Japan redefines functional foods. Prepared Foods. 1998; 167(5): 129-131.

36. Kwak N.-S, Jukes D. Issues in the substantiation process of health claims. Crit Rev Food Sci Nutr. 2001; 41: 465-479.

37. Lappalainen R, Kearney J, Gibney M. A pan EU survey of consumer attitudes to food, nutrition and health: an overview. Food Qual Prefer. 1998; 9(6): 467-478.

38. Lucchina L. Improving the success of functional foods. Food Technology. 2003; 57: 42-47.

39. Menrad K. Market and marketing of functional food in Europe. J Food Eng. 2003; 56: 181-188.

40. Mollet B, Rowland I. Functional foods. At the frontier between food and pharma. Curr Opin Biotechnol. 2002; 13: 483-485.

41. Niva M. 'All foods affect health'. Understandings of functional foods and healthy eating among health-oriented Finns. Appetite. 2007; 48: 384-393.

42. Nunnally J. C. Psychometric theory. New York: McGraw-Hill. 1978. 
43. Poulsen J. Danish consumers' attitudes towards functional foods (MAPP Working Paper No. 62). 1999.

44. Prättälä R. Dietary changes in Finland-success stories and future challenges. Appetite, 41(3), 245249. Appetite. 2003; 41: 245-249.

45. Roberfroid M. B. Prebiotics and probiotics: are they functional foods? Am. J. Clin. Nutr. 2000; 71(6): 1682S-1687S.

46. Roberfroid M. B. A European consensus of scientific concepts of functional foods. Nutrition. 2000; 16: 689-691.

47. Roberfroid M. B. Global view on functional foods: European perspectives. Br. J. Nutr. 2002; 88(S2): S133-S138.

48. Saba A. Cross-cultural differences in food choice. In L. Frewer E. Risvik H Schifferstein (Eds.), Food, people and society. A Eur Perspect Consum. 2001.

49. Sarstedt M. A review of recent approaches for capturing heterogeneity in partial least squares path modelling. J Model Manag. 2008; 3(2): 140-161.

50. Sibbel A. The sustainability of functional foods. Soc Sci Med. 2007; 64: 554-561.

51. Stanton C, Gardiner G, Lynch P, Collins J, Fitzgerald G, Ross R. Probiotic cheese. Int Dairy Journal.1998; 8(5-6): 491-496.

52. Stanton C, Ross R. P, Fitzgerald G. F, Van Sinderen D. Fermented functional foods based on probiotics and their biogenic metabolites. Curr Opin Biotechnol. 2005; 16: 198-203.

53. Steptoe A, Pollard T. M, Wardle J. Development of a measure of the motives underlying the selection of food: the food choice questionnaire. Appetite. 1995; 25(3): 267-284.

54. Tamime A, Saarela M, Sondergaard A. K, Mistry V, Shah N. Production and maintenance of viability of probiotic microorganisms in dairy products. Probiotic dairy Prod. 2005; 39-72. https://doi.org/10.1002/9780470995785.ch3.

55. Tudoran A, Olsen S. O, Dopico D. C. The effect of health benefits information on consumers' health value, attitudes and intentions. Appetite. 2009; 52(3): 568-579.

56. Urala N, Lähteenmäki L. Reasons behind consumers' functional food choices. Nutr Food Sci. 2003; 33: $148-158$.

57. Urala N, Lähteenmäki L. Attitudes behind consumers' willingness to use functional foods. Food Qual Prefer. 2004; 15(7-8): 793-803.

58. Verbeke W. Consumer acceptance of functional foods. Socio-demographic, cognitive and attitudinal determinants. Food Qual. Prefer. 2005; 16(1): 45-57.

59. Verbeke W. Functional foods: Consumer willingness to compromise on taste for health? Food Qual. Prefer. 2006: 17(1-2): 126-131.

60. Vinzi V. E, Trinchera L, Amato S. PLS path modeling: from foundations to recent developments and open issues for model assessment and improvement Handbook of partial least squares. Springer. 2010; 47-82 
61. Weststrate J. A, van Poppel G, Verschuren P. M. Functional foods, trends and future. Br J Nutr. 2002; 88(Suppl 2): S233-S235.

62. Young Y. Functional foods and the European consumer. In J. Buttriss \& M. Saltmarsh (Eds.), Functional foods. II. Claims and evidence. London, UK: The Royal Society of Chemistry. 2000.

63. Zhu C, Lopez R. A, Liu X. Information cost and consumer choices of healthy foods. Am J Agric Econ. 2015; 98(1): 41-53.

\section{Figures}

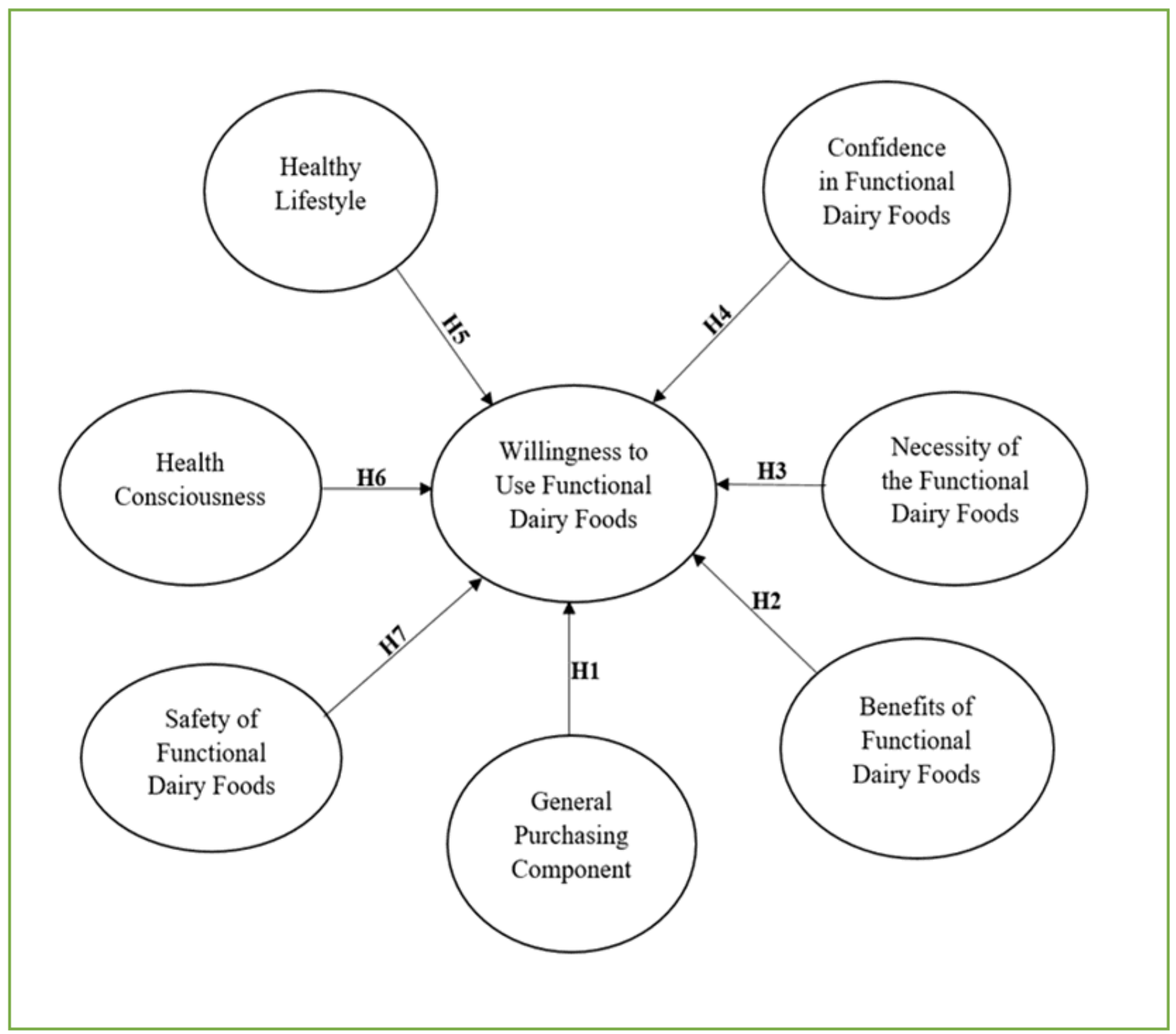

Figure 1

Conceptual model for investigating the effect of attitude components. 


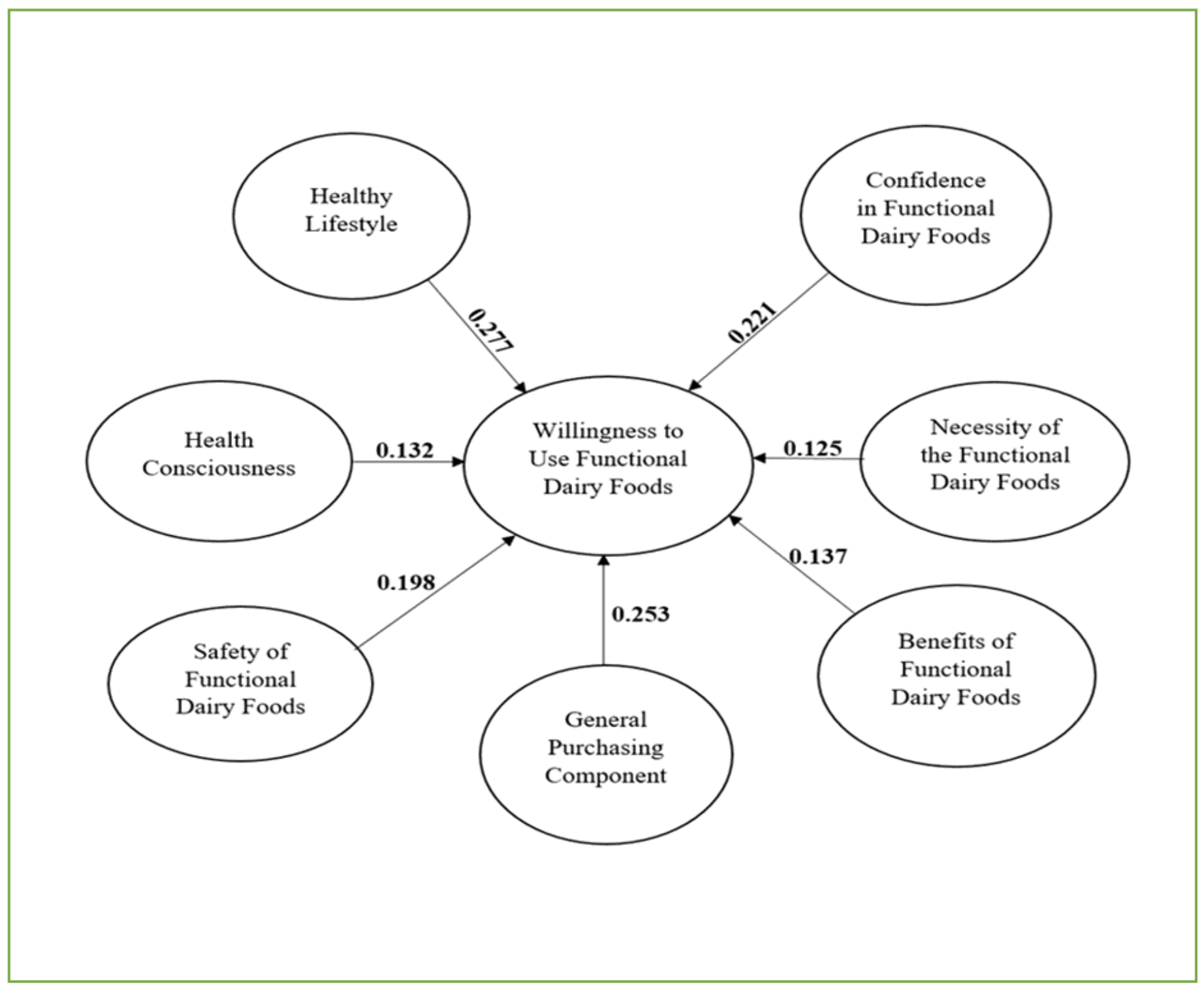

Figure 2

Estimated model for attitude factors affecting the acceptance of functional dairy. 


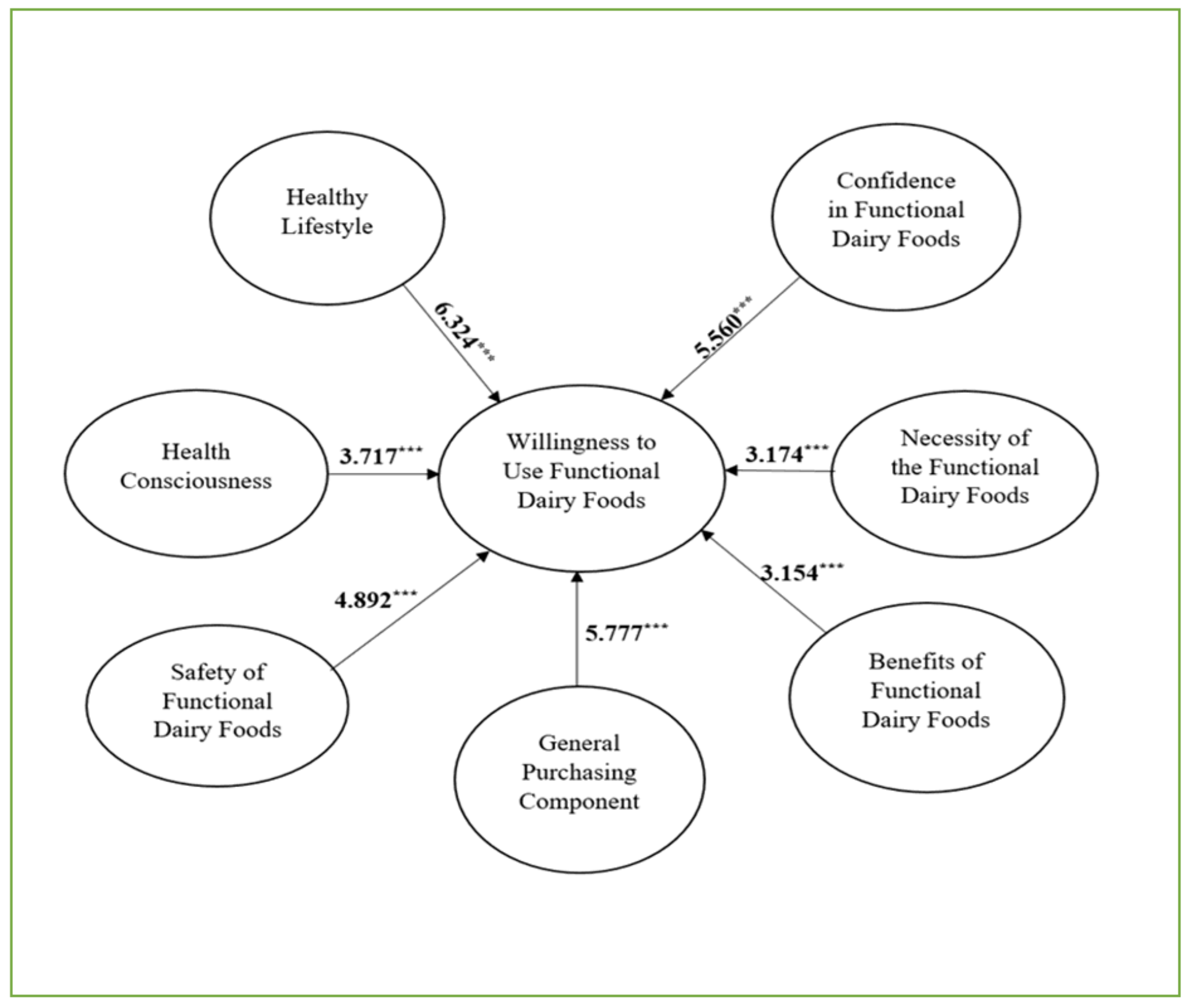

Figure 3

Significance of the PLS model coefficients. 